\title{
Phytochemical, antioxidant and protective effect of Rhus tripartitum root bark extract against ethanol-induced ulcer in rats
}

\author{
Hichem Alimi ${ }^{1,2}$, Sakhria Mbarki ${ }^{3}$, Zeineb Ben Barka ${ }^{2}$, Anwer Feriani ${ }^{3}$, Zouhour Bouoni ${ }^{3}$, \\ Najla Hfaeidh ${ }^{3}$, Mohsen Sakly ${ }^{2}$, Olfa Tebourbi² and Khémais Ben Rhouma ${ }^{2}$ \\ ${ }^{1}$ Research unit of Macromolecular Biochemistry and Genetic, Faculty of Sciences of Gafsa, 2112 Gafsa, Tunisia \\ ${ }^{2}$ Laboratory of Integrated Physiology, Faculty of Science of Bizerte, 7021 Jarzouna, Bizerte, Tunisia \\ ${ }^{3}$ Laboratory of Animal Ecophysiologie, Faculty of Science of Sfax, 3018 Sfax, Tunisia
}

\begin{abstract}
Rhus tripartitum (sumac) is an Anacardiaceae tree with a wide phytotherapeutic application including the use of its roots in the management of gastric ulcer. In the present study the Rhus tripartitum root barks extract (RTE) was phytochemical studied, in vitro tested for their potential antioxidant activity using 2,2-diphenyl-1-picrylhydrazyl (DPPH) and reducing power assay and in vivo evaluated for its ability to prevent ethanol-induced gastric ulcer in rats. The RTE was rich in phenolics, flavonoids, tannins and polysaccharide contents and exhibited a low but not weak in vitro antioxidant activity when compared with (+)-catechin. Pre-treatment with RTE at oral doses 50, 200 and $400 \mathrm{mg} / \mathrm{kg}$ body weight was found to provide a dose-dependent protection against ethanolinduced ulcer by averting the deep ulcer lesions of the gastric epithelium, by reducing gastric juice and acid output, by enhancing gastric mucus production by preserving normal antioxidant enzymes activities, and inhibiting the lipid peroxidation. The antiulcerogenic activity of RTE might be due to a possible synergistic antioxidant and antisecretory effects.
\end{abstract}

Key words: Rhus tripartitum - Polysaccharide - Tannin — Antioxidant - Antiulcerogenic

\begin{abstract}
Abbreviations: CAT, catalase; DPPH, 2,2-diphenyl-1-picrylhydrazyl; FT-IR, Fourier transform infrared; FRAP, ferric reducing antioxidant power; GPx, glutathione peroxidase; MDA, malondialdehyde; MPO, myelo-peroxidase; PSC, polysaccharide content; Ran, ranitidine; RTE, Rhus tripartitum root barks extract; SOD, superoxide dismutase; TCT, total condensed tannins; TFC, total flavonoid content; TPC, total phenolic content.
\end{abstract}

\section{Introduction}

The term peptic ulcer disease is commonly used to refer to ulcerations of the stomach, duodenum, or both. Approximately 4 million recurrences of peptic ulcers occur in the United States each year (Chugh and Aronow 2011). Moreover, an estimated 15,000 deaths per year occur as a consequence of complicated peptic ulcer disease (Valle 2008). Gastric ulcer demonstrates a morphological defect that extends through the muscularis mucosa into the sub-

Correspondence to: Hichem Alimi, Research unit of Macromolecular Biochemistry and Genetic, Faculty of Sciences of Gafsa, 2112 Gafsa, Tunisia

E-mail: alimihichem@yahoo.fr mucosa or deeper (Singh et al. 2008). The pathophysiology of these ulcers involves an imbalance between offensive (acid and pepsin) and defensive factors (mucin, prostaglandin and bicarbonate, etc.) (Arun and Asha 2008). The infection with Helicobacter pylori and the uses of non-steroid anti-inflammatory drugs (NSAIDs) are identified as promoters of gastric ulcer development (O'Malley 2003). In addition, we have previously demonstrated that acute ethanol consumption results in gastric ulcer evidenced by acute hemorrhagic lesions, mucosal edema, epithelial exfoliation, inflammatory cell infiltration and alterations in the cell redox state (Alimi et al. 2010, 2011). A number of products have been used for the treatment of gastric ulcers such as antihistaminics, proton pump inhibitors or antacids, but most of these drugs produce several adverse reactions (Singh et al. 2008). This 
has been the basis for the development of more effective and safe antiulcer drugs which includes herbal drugs. In this respect, our laboratory gives a high interest to the protective potential of sumac plants as regards ulcer resulted from acute ethanol toxicity.

Rhus tripartitum (sumac) (Anacardiaceae) is a native presaharian Tunisian plant (North Africa) with great economical and ecological interests. In Tunisia Rhus tripartitum fruits are consumed fresh, soaked in sour milk or added to drinking water to offer an acceptable taste (Mahjoub et al. 2010). The Rhus tripartitum root barks are used in traditional Tunisian medicine for their antiulcerogenic effect. It has been demonstrated that Rhus tripartitum aerial parts (leaves, stems, and fruits) are rich in biflavonoids and expressed an antioxidants and an anti-inflammatory effects (Mahjoub et al. 2010). But there is no information hitherto about the ability of Rhus tripartitum root barks to counteract ulcer development. Therefore, we investigated whether the 50\% methanolic extract of Rhus Tripartitum root barks has an antioxidant activity and whether it could prevent ethanolinduced ulcer in rats.

The aim of the present study was to investigate, as a first approach, the chemical compounds and the in vitro antioxidants activity of the Rhus tripartitum root barks methanolic extract (RTE). The RTE was then in vivo tested for its antiulcerogenic activity by measuring the lipid peroxidation level in rat stomach tissues, expressed as malondialdehyde (MDA), the activities of some gastric antioxidant enzymes such as superoxide dismutase (SOD), catalase (CAT), glutathione peroxidase (GPx), and myeloperoxidase (MPO), the histopathologic changes, the $\mathrm{pH}$ and volume of gastric juice, ulcer area and curative ratio were also estimated.

\section{Materials and Methods}

\section{Plant material and preparation of extract}

The Rhus tripartitum roots were collected at the beginning of March 2012 in Djebel Thelja, Gafsa, state of Tunisia. A voucher specimen (R.T.H03-N06) was identified and authenticated by a Taxonomist, Dr. Boulbaba Ltayef, and deposited at the herbarium (H03) in the Faculty of Sciences, University of Gafsa, Tunisia. The Rhus tripartitum root barks were cleaned, dried under shade, grounded to a fine powder and extracted ( $50 \mathrm{~g}$ ) with $500 \mathrm{ml}$ of methanol (50\%), for $24 \mathrm{~h}$ at room temperature with magnetic stirring. The extract was centrifuged at $4500 \times g$ for $10 \mathrm{~min}$ and lyophilized. The RTE yielded $22.62 \mathrm{~g}$ of brown residue was stored at $-21^{\circ} \mathrm{C}$ until use. The yielded RTE is totally soluble when dissolved in distilled water and gives a slightly viscous brown solution.

\section{Chemicals}

Ethanol was purchased from Carlo Erba Reagents, trichloroacetic acid (TCA), butylated hydroxytoluene (BHT), 2-thiobarbituric acid (TBA), dithiobis-2-nitrobenzoic acid (DTNB), 2,2-diphenyl-1-picrylhydrazyl (DPPH), aluminum chloride $\left(\mathrm{AlCl}_{3}\right)$ and Folin-Ciocalteu reagent were purchased from Sigma chemical Co. (St. Louis, MO, USA). All other used chemicals and reagents were for analytic grades.

\section{Phytochemical studies of RTE}

\section{Determination of total phenolic content}

The total phenolic content (TPC) was determined using the Folin-Ciocalteu method described by Singleton et al. (1999). A $125 \mu$ volume of RTE dissolved in distilled water was mixed with $0.5 \mathrm{ml}$ of $10 \%$ diluted Folin-Ciocalteu reagent $(\mathrm{v} / \mathrm{v})$ and $1 \mathrm{ml}$ of $7.5 \%$ saturated sodium carbonate $(\mathrm{w} / \mathrm{v})$. The reaction mixture was incubated at $45^{\circ} \mathrm{C}$ for $40 \mathrm{~min}$, and the absorbance was measured at $765 \mathrm{~nm}$ by Analytik Jena 40 spectrophotometer. The amount of total phenolics is expressed as gallic acid equivalents (GAE, mg gallic acid/g of RTE) through the calibration curve ranged $0-50 \mu \mathrm{g} / \mathrm{ml}\left(\mathrm{R}^{2}=\right.$ 0.9986) and all tests were carried out in triplicate.

\section{Determination of total flavonoid content}

The total flavonoid content (TFC) was determined using a method described by Djeridane et al. (2006). One milliliter of RTE aqueous solution was mixed with $1 \mathrm{ml}$ of $2 \%$ methanolic $\mathrm{AlCl}_{3} \cdot 6 \mathrm{H}_{2} \mathrm{O}$. After incubation for $15 \mathrm{~min}$ at room temperature, the absorbance of the reaction mixture was measured at $430 \mathrm{~nm}$. The amount of total flavolnoid content is expressed as rutin equivalents ( $\mathrm{mg} \mathrm{RE} / \mathrm{g}$ of RTE) through the calibration curve ranged $0.5-40 \mu \mathrm{g} / \mathrm{ml}\left(\mathrm{R}^{2}=\right.$ 0.9989 ) and all tests were carried out in triplicate.

\section{Determination of total condensed tannins}

The total condensed tannins (TCT, proanthocyanidin) were extracted from RTE using acetone-water mixture according to Tebourbi et al. (2006). Briefly, $100 \mathrm{mg}$ of RTE was dissolved in $1 \mathrm{ml}$ of acetone-water $(90 / 10 \mathrm{v} / \mathrm{v})$, vortexed for $2 \mathrm{~min}$ and centrifuged at $10.000 \times g$ for $10 \mathrm{~min}$. The total condensed tannins of the supernatant were determined by the vanillin- $\mathrm{H}_{2} \mathrm{SO}_{4}$ method (Baoshan et al. 1998). Briefly, $200 \mu \mathrm{l}$ of supernatant was added to $500 \mu \mathrm{l}$ of $1.2 \%$ vanillin solution and $500 \mu \mathrm{l}$ of $20 \% \mathrm{H}_{2} \mathrm{SO}_{4}$ solution. The reaction was carried out in the dark at room temperature for $20 \mathrm{~min}$, and then absorbance was measured at $500 \mathrm{~nm}$. The amount of TCT is expressed as (+)-catechin equivalents ( $\mathrm{mg} \mathrm{CE} / \mathrm{g} \mathrm{RTE})$. The calibration curve ranged $0-300 \mu \mathrm{g} / \mathrm{ml}\left(\mathrm{R}^{2}=0.9978\right)$. 


\section{Estimation of RTE polysaccharide content}

An amount of RTE ( $2 \mathrm{~g}$ ) was dissolved in $20 \mathrm{ml}$ of distilled water and heated at $80^{\circ} \mathrm{C}$ for $2 \mathrm{~h}$. The obtained solution was then precipitated overnight at $4^{\circ} \mathrm{C}$ by adding ethanol (four times the volume of extract solution), followed by centrifugation at $4500 \times g$ for $10 \mathrm{~min}$. The precipitate was dissolved in $20 \mathrm{ml}$ of distilled water and deproteinised by Sevag reagent (chloroform/butanol 4:1, v/v) as described by Navarini et al. (1999). The resulting aqueous fraction was extensively dialyzed against double-distilled water for three days and again precipitated by adding four-fold volume of ethanol. After centrifugation, the precipitate was washed with anhydrous ethanol, dissolved in distilled water and lyophilized. The extract yield of RTE polysaccharide was measured by employing sulfuric acid-phenol method (Dubois et al. 1956) using D-glucose as a standard. All tests were carried out in triplicate and the amount polysaccharide content (PSC) was expressed as $\mathrm{mg} / \mathrm{g}$ of RTE.

Fourier transform infrared spectral analysis of RTE polysaccharide

Fourier transform infrared (FT-IR) spectra of the RTE polysaccharide were recorded on FT-IR Shimadzu, FTIR8400S spectrophotometer equipped with IRsolution 1.10 Shimadzu software in the range of $4000-500 \mathrm{~cm}^{-1}$. FT-IR scans were collected on completely dried thin films of the RTE polysaccharide cast on $\mathrm{KBr}$ discs. The spectra covered the infrared region $4000-500 \mathrm{~cm}^{-1}$, the number of scans per experiment was 10 and resolution was $6 \mathrm{~cm}^{-1}$.

\section{Extraction and HPLC analysis of RTE phenolic acids}

Rhus tripartitum extract ( $1 \mathrm{~g}$ ) was mixed with $10 \mathrm{ml}$ of $80 \%$ methanol, and kept under magnetic stirring at room temperature for $24 \mathrm{~h}$ and then centrifuged at $10,000 \times g$ for $10 \mathrm{~min}$. The upper layer was then treated with acetone $(1: 4 \mathrm{v} / \mathrm{v})$ and centrifuged for $10 \mathrm{~min}$ at $10,000 \times g$ to precipitate pigments. Prior to high-performance liquid chromatography (HPLC) analysis, the extract was dried using a mini Speed Vac to remove organic solvent then dissolved in deionized water and filtrated through nylon syringe filters, $0.45 \mu \mathrm{m}$ (Carl Roth GmbH, Karlsruhe, Germany).

The HPLC analysis of the RTE phenolic acids was carried out using a Varian Prostar HPLC equipped with a C-18 reverse phase column (Varian, $150 \mathrm{~mm} \times 4.6 \mathrm{~mm}$, particle size $5 \mu \mathrm{m}$ ), a ternary pump (model Prostar 230) and a Prostar 330 diode array detector at an isocratic elution. Eluant was water/acetonitrile/methanol (50/25/25 v:v), the flow rate was $0.8 \mathrm{ml} \cdot \mathrm{min}^{-1}$ and the injection volume was $25 \mu \mathrm{l}$ at $25^{\circ} \mathrm{C}$. The identification were performed at $254 \mathrm{~nm}$ based on the comparison with the retentions times and by co-injection of phenolic acids standards.

\section{In vitro antioxidant activity of RTE}

\section{$D P P H$ radical-scavenging activity}

The free radical scavenging activity of RTE was evaluated with the DPPH radical assay according to the method reported by Grzegorczyk et al. (2007). Aqueous solution of RTE $(1 \mathrm{ml})$ at various concentrations $(2-500 \mu \mathrm{g} / \mathrm{ml})$ was added to $1 \mathrm{ml}$ of a $0.1 \mathrm{mM}$ methanolic solution of $\mathrm{DPPH}$ and allowed to stand for $30 \mathrm{~min}$ at $27^{\circ} \mathrm{C}$. The absorbance of the sample was then measured at $517 \mathrm{~nm}$. (+)-Catechin was used as a reference in the same concentration range as the test extract. A control solution, without a tested compound, was prepared in the same manner as the assay mixture. All the analyses were done in triplicate. The degree of the reaction mixture bleaching indicates the radical-scavenging efficiency of the extract. The antioxidant activity of RTE was calculated as an inhibitory effect (IE\%) of the DPPH radical formation as follows:

$$
\mathrm{IE} \%=\mathrm{A}_{\mathrm{DPPH}}-\left(\mathrm{A}_{\text {sample }}-\mathrm{A}_{\text {control }}\right) / \mathrm{A}_{\mathrm{DPPH}} \times 100
$$

where $A_{\mathrm{DPPH}}$ is the absorbance of DPPH solution without sample extract, $A_{\text {sample }}$ is the absorbance of sample extract mixed with DPPH solution and $\mathrm{A}_{\text {control }}$ is the absorbance of the sample extract tested without $\mathrm{DPPH}$. The $\mathrm{EC}_{50}$ value was defined as the concentration (in $\mu \mathrm{g} / \mathrm{ml}$ ) of the RTE required for scavenging the DPPH radical by $50 \%$.

\section{Ferric reducing antioxidant power}

The reducing property of the RTE was determined by assessing its ability to reduce $\mathrm{Fe}^{3+}$-ferricyanide complex as described by Chu et al. (2000). Briefly $2.5 \mathrm{ml}$ of potassium phosphate buffer $(0.1 \mathrm{M}, \mathrm{pH} 6.6)$ was mixed with $2.5 \mathrm{ml}$ of $1 \%(\mathrm{w} / \mathrm{v})$ potassium ferricyanide and $1.0 \mathrm{ml}$ of RTE solution at varying concentration $(5-1000 \mu \mathrm{g} / \mathrm{ml})$. The mixture was incubated at $50^{\circ} \mathrm{C}$ for $20 \mathrm{~min}$, thereafter $2.5 \mathrm{ml}$ of $10 \%(\mathrm{w} / \mathrm{v})$ trichloroacetic acid was added, and subsequently centrifuged at $1000 \times g$ for $10 \mathrm{~min}, 2.5 \mathrm{ml}$ of the supernatant was mixed with equal volume of water and $0.5 \mathrm{ml}$ of $0.1 \%(\mathrm{w} / \mathrm{v})$ ferric chloride. The absorbance was then measured at $700 \mathrm{~nm}$; a higher absorbance indicates a higher ferric reducing antioxidant power (FRAP). (+)-Catechin was used as standards for comparison and the test were carried out in triplicate.

\section{Antiulcerogenic activity of RTE}

\section{Experimental animals}

Adult male Wistar rats weighing 240-260 g purchased from SIPHAT (Tunis, Tunisia) were used for the acute toxicity and antiulcerogenic studies. Before any experience, all animals 
were kept for 2 weeks adaptation period under the same laboratory conditions of temperature $\left(22 \pm 2^{\circ} \mathrm{C}\right)$, relative humidity $(70 \pm 4 \%)$ and a $12 \mathrm{~h}$ light/dark cycle, and received a nutritionally standard diet (SICO, Tunisia) and tap water. All animals were fasted prior all assays and kept in cages with raised floors of wide mesh to prevent coprophagia. Standard drugs and RTE were administered orally by gastric intubation. Animals were cared for under the Tunisian code of practice for the Care and Use of Animals for Scientific Purposes.

\section{Acute toxicity of RTE}

A total of 32 rats were randomly divided into four groups $(n=8)$. First group served as normal control. Groups two, three and four received RTE dissolved in distilled water at the dose level of 1000, 2000, $3000 \mathrm{mg} / \mathrm{kg}$ p.o., respectively. All animals were observed for toxic symptoms and mortality for $72 \mathrm{~h}$.

\section{Effect of RTE on ethanol-induced ulcers in rats}

The total of 48 rats were divided into six treatment groups $(n=8)$ and fasted for $24 \mathrm{~h}$ prior treatment though water was allowed ad libitum. The treatment of these groups is made in two steps; firstly they receive vehicle, RTE or ranitidine (Ran) dissolved in distilled water. Ranitidine was used as standard antiulcer drug, which act as a gastric anti-acid output (Shaker et al. 2010). One hour after the first treatment, all the groups except control group, were orally treated with 0.5 $\mathrm{ml}$ of ethanol ( $80 \%$ in water) for the gastric ulcer induction according to the scheme described in Figure 1. One hour later, the animals were sacrificed, their stomachs ligatured in esophageal and pyloric canals, excised and photographed. The stomachs were then opened along the greater curvature; the gastric juice and the mucus covering each stomach were then carefully collected into clean tubes. This were centrifuged at $12,000 \times g, 4^{\circ} \mathrm{C}$ for $10 \mathrm{~min}$ and analyzed for gastric juice volume, $\mathrm{pH}$ value, and mucus weight. Each stomachs were then rinsed with saline solution $(0.9 \%)$, photographed and the extent of the lesions were measured $\left(\mathrm{mm}^{2}\right)$ and taken as ulcer index according to the method of Khan (2004) using the ImageJ software (National Institute of Health).

\section{Biochemical analysis}

The mucosal tissues ( 0.5 g each) were grinded with liquid nitrogen in a mortar and homogenised by an Ultra-Turraks in $4.5 \mathrm{ml}$ of cold phosphate buffer $(50 \mathrm{mmol} / \mathrm{l}, \mathrm{pH} 7.4 ; 5 \mathrm{mmol}$ $\mathrm{BHT}$ ). The butylated hydroxytoluene was used to prevent new lipid peroxidation that can occur during homogenisation. The homogenate was then centrifuged at $12,000 \times g$ at $4^{\circ} \mathrm{C}$ for 10 min. Supernatant was aliquoted and stored at $-80^{\circ} \mathrm{C}$ until determination of SOD, CAT, glutathione peroxidase (GSH-Px) and MPO activities and total protein, total glutathione (GSH) and malondialdehyde (MDA) contents.

In stomach homogenate SOD activity was estimated according to the method described by Misra and Fridovich (1972). CAT activity was determined by measuring hydrogen peroxide decomposition at $240 \mathrm{~nm}$ according to the method described by Aebi (1984). GSH-Px activity was assayed by the subsequent oxidation of NADPH at $240 \mathrm{~nm}$, using the method described by Flohe and Gunzler (1984). The protein content stomach homogenate were determined according to Lowry's method using bovine serum albumin as standard (Lowry 1951). The level of lipid peroxidation was measured as MDA content according to the method of Ohkawa et al. (1979). Total GSH contents were measured by Ellman's reaction using 5,5-dithiobis 2-nitrobenzoic acid according to the method of Moron et al. (1979). All assays were carried out at room temperature in triplicate.

\section{Histopathological studies}

After the macroscopic analyses small portion of each stomach tissues was fixed in $4 \%$ formalin solution, dehydrated

\begin{tabular}{|c|c|c|c|c|}
\hline Treatments & $0 \mathrm{~min}$ & $60 \mathrm{~min}$ & $120 \mathrm{~min}$ & Time \\
\hline Control & Saline solution & Saline solution & & \\
\hline $\mathrm{EtOH}$ & Saline solution & Ethanol & & \\
\hline RTE1+ EtOH & RTE1 $(50 \mathrm{mg} / \mathrm{kg})$ & Ethanol & Sacrifice & \\
\hline $\mathrm{RTE} 2+\mathrm{EtOH}$ & RTE2 $(200 \mathrm{mg} / \mathrm{kg})$ & Ethanol & & \\
\hline RTE3+ EtOH & RTE3 $(400 \mathrm{mg} / \mathrm{kg})$ & Ethanol & & \\
\hline $\mathrm{Ran}+\mathrm{EtOH}$ & $\operatorname{Ran} \quad(50 \mathrm{mg} / \mathrm{kg})$ & Ethanol & & \\
\hline
\end{tabular}

Figure 1. Scheme of drugs treatments. RTE1, RTE2 and RTE3 are the groups respectively treated with $50 \mathrm{mg} / \mathrm{kg}, 200 \mathrm{mg} / \mathrm{kg}$ and $400 \mathrm{mg} /$ $\mathrm{kg}$ b.w of RTE. Ethanol was prepared in distilled water as $80 \% \mathrm{v} / \mathrm{v}$ and instilled as $0.5 \mathrm{ml} / \mathrm{rats}$ for each group except control group. RTE, Rhus tripartitum extract, EtOH: ethanol, Ran: ranitidine. 
through ascending grades of alcohol, and embedded in paraffin. Five micrometer sections were made using microtome, and stained with hematoxylin-eosin solutions (H\&E). Tissue preparations were observed and micro-photographed under a light $\mathrm{BH} 2$ Olympus microscope.

\section{Statistical analysis}

Statistical analysis was performed using one-way ANOVA followed by Tukey's test and significance of difference between treatments was accepted at $p<0.05$. Data are expressed as mean \pm standard deviation of the means.

\section{Results}

\section{Phytochemical studies of RTE}

The methanolic extract of Rhus tripartitum root barks yielded $22.62 \mathrm{~g}$ which expressed $45.24 \%$ of initial weight used (50 g). The phytochemical studies of RTE revealed the presence of high amount of phenolic contents (122.88 \pm $0.51 \mathrm{mg} \mathrm{GAE} / \mathrm{g}$ ) when compared with the phenolics contents detected in the root extract of Opuntia ficus indica $f$. inermis ( $57.56 \pm 0.51 \mathrm{mg} \mathrm{GAE} / \mathrm{g})$, demonstrated to have an antiulcerogenic effects (Alimi et al. 2010). On the other hand, the chemical studies of RTE show a substantial content of flavonoids (9.12 $\pm 0.22 \mathrm{mg} \mathrm{RE} / \mathrm{g})$ when compared with the aqueous root extract of Rhus pentaphyllum (Ben Mansour et al. 2011). In addition higher tannin content (57.53 $\pm 0.64 \mathrm{mg} \mathrm{CE} / \mathrm{g}$ ) have been detected in RTE when compared with the level $(25.33 \pm 0.07 \mathrm{mg} \mathrm{CE} / \mathrm{g})$ detected in fresh root bark extract of Rhus oxyacantha (Tebourbi et al. 2006). Where as RTE polysaccharide content (126.78 \pm 0.59 $\mathrm{mg} / \mathrm{g}$ of extract) appeared lower then that the level $(600 \mathrm{mg} /$ $\mathrm{g}$ of extract) detected in Decalepis hamiltonii root known for their antiulcerogenic effect (Srikanta et al. 2007).

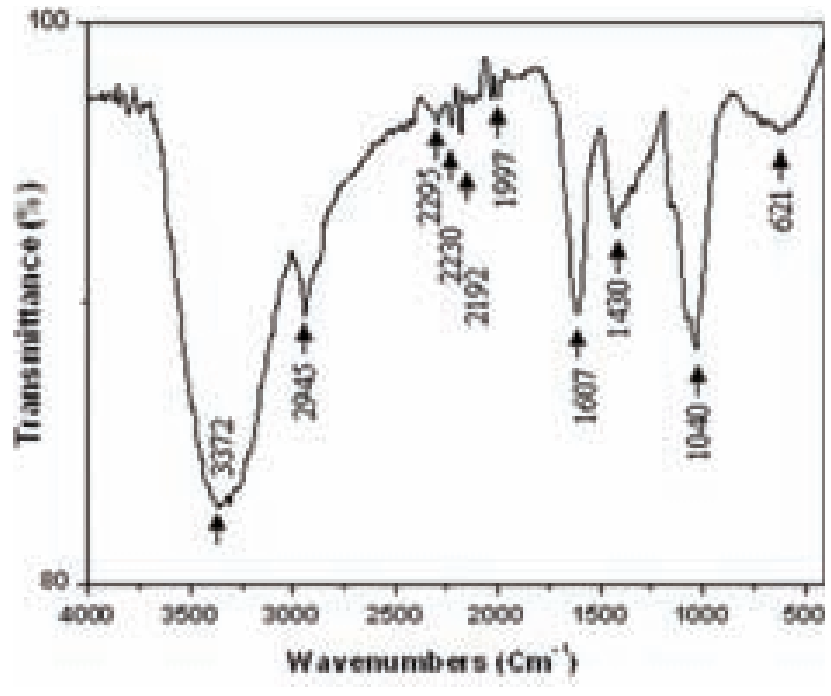

Figure 2. Infrared spectra of the polysaccharide extracted from Rhus tripartitum extract (RTE) recorded in the frequency range $4000-500 \mathrm{~cm}^{-1}$.

The FT-IR analysis of RTE purified polysaccharide (Fig. 2) displayed a broad stretching intense peak at $3372 \mathrm{~cm}^{-1}$ which is the characteristic absorption of hydroxyl groups followed by weak $\mathrm{C}-\mathrm{H}$ stretching bands at $2945 \mathrm{~cm}^{-1}$ (Xu et al. 2009). The weak peaks were their bands range $2995-1997 \mathrm{~cm}^{-1}$ are non identified compounds. The RTE polysaccharide also contains uronic acids, characterized by the carboxylic group which could lead to two absorbance peaks. The band towards $1607 \mathrm{~cm}^{-1}$ was attributed to the stretching vibration of $\mathrm{C}=\mathrm{O}$ in protonated carboxylic acid. The band towards $1430 \mathrm{~cm}^{-1}$ was attributed to the absorbance of the $\mathrm{COO}^{-}$deprotonated carboxylic group (Manrique and Lajolo 2002). The peak observed at 1040 $\mathrm{cm}^{-1}$ in the FT-IR spectrum of RTE could be characteristic of rhamnose polysaccharide content and the peak observed

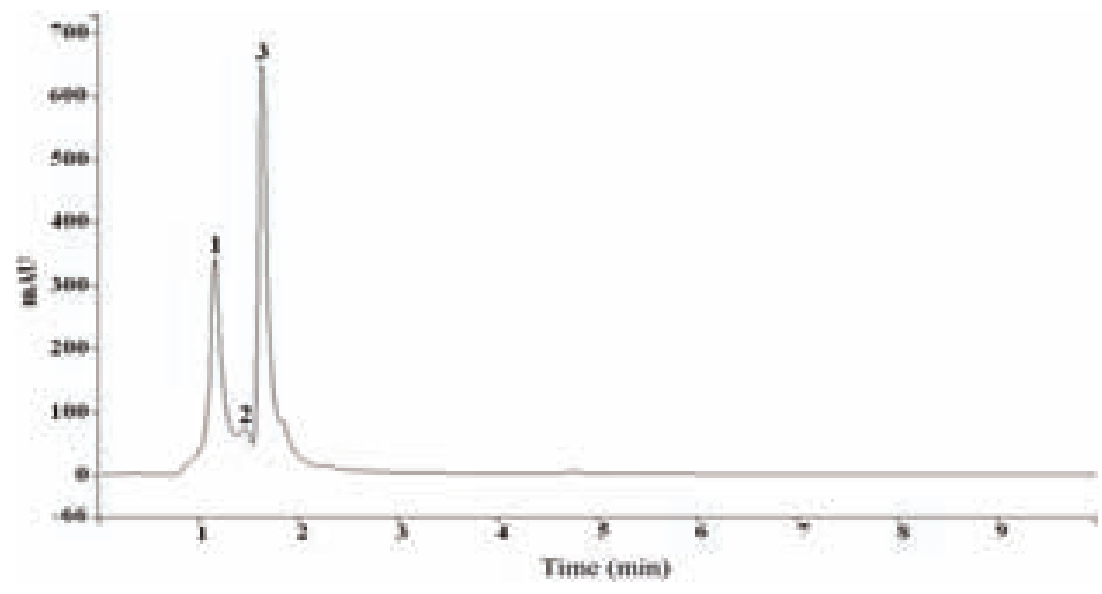

Figure 3. HPLC elution profile of phenolic acids $(\lambda=254 \mathrm{~nm})$ from Rhus tripartitum extract (RTE) showed non identified phenolic acids (1 and 2) and a large content of gallic acid (3). The HPLC analyses were performed using a Varian Prostar HPLC equipped with a reverse phase C- 18 column (Varian, $150 \mathrm{~mm}$ $\times 4.6 \mathrm{~mm}$, particle size $5 \mu \mathrm{m}$ ) on conjunction with isocratic elution: Water/Acetonitrile/ Methanol (50/25/25 v:v). The flow rate was $0.8 \mathrm{ml} \mathrm{min}{ }^{-1}$ and the injection volume was $25 \mu \mathrm{l}$ at $25^{\circ} \mathrm{C}$. 


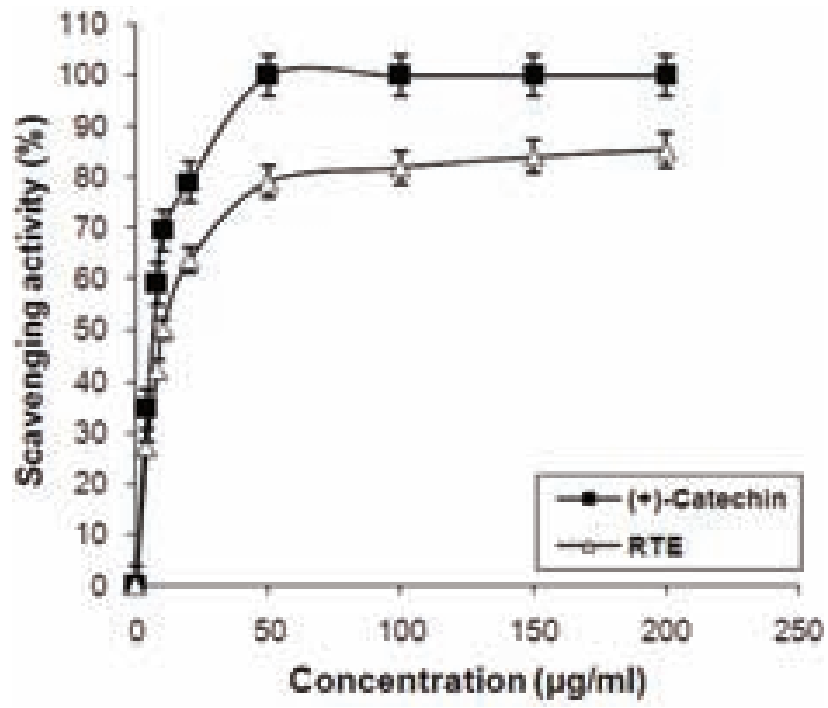

Figure 4. Scavenging activity of Rhus tripartitum extract (RTE) on DPPH radicals. (+)-Catechin was used as a positive control.

at $621 \mathrm{~cm}^{-1}$ could be characteristic of $\beta$-D-glucose (Zhao et al. 2007).

The HPLC analysis of RTE at $254 \mathrm{~nm}$ (Fig. 3) revealed the presence of large content of gallic acid (peak 3 ) and two other non identified compounds (peaks 1 and 2).

\section{Antioxidant activity of RTE}

As shown in Fig. 4, the radical scavenging activity of RTE and (+)-catechin on DPPH radicals increased as concentrations increase and reach the maximum of inhibition at $200 \mu \mathrm{g} / \mathrm{ml}$ and $50 \mu \mathrm{g} / \mathrm{ml}$, respectively. The $\mathrm{EC}_{50}$ values calculated from the graph (Fig. 4) shows that the radical-scavenging activity of RTE $\left(\mathrm{EC}_{50}=10 \pm 0.1 \mu \mathrm{g} / \mathrm{ml}\right)$ appeared lower than that of $(+)$-catechin $\left(\mathrm{EC}_{50}=6.77 \pm 0.2 \mu \mathrm{g} / \mathrm{ml}\right)$.

The reducing propriety of RTE tested against $\mathrm{Fe}^{3+}$ (Fig. 5) increased with increase of concentrations and reaches a maximum at $1000 \mu \mathrm{g} / \mathrm{ml}$ which was significantly lower $(p<0.05)$ than that of $(+)$-catechin $(200 \mu \mathrm{g} / \mathrm{ml})$. The effective concentration $\left(\mathrm{EC}_{50}\right)$ of RTE $\left(\mathrm{EC}_{50}=340.94 \pm 0.7 \mu \mathrm{g} / \mathrm{ml}\right)$ providing 0.5 of absorbance, calculated from the graph (Fig. 5), appeared significantly $(p<0.05)$ lower than that of $(+)$-catechin $\left(\mathrm{EC}_{50}=42.06 \pm 0.3 \mu \mathrm{g} / \mathrm{ml}\right)$ used as standard.

\section{Antiulcerogenic activity of RTE}

\section{Acute toxicity of RTE}

The acute toxicity studies demonstrate that oral administration of RTE up to $3000 \mathrm{mg} / \mathrm{kg}$ b.w., did not cause any toxic effect and no mortality was observed in treated rats.
Effect of RTE on ethanol-induced ulcers in rats

The effects of orally administered RTE on gastric ulcer induced on rats by $80 \%$ ethanol solution are showed in Fig. 6. The ethanol-ulcerated rats $(\mathrm{EtOH})$ showed a large and swelled stomach full of gastric juice in comparison with control rats. When ulcerated rats are pre-treated with RTE we assist to the reduction of the whole stomach size as dose-dependant manner to reach a near normal size seen at control and ranitidine (Ran) groups. The photographs of the dissected and sectioned stomach revealed a deep hemorrhagic lesion of mucosal layer (Fig. 6: 1 and a, arrows) and a numerous neutrophil infiltration (Fig. 6: b, circle). The Stomach of ulcerated rats treated with low dose of RTE (50 mg/kg b.w.) exhibited no deep gastric lesions (Fig. 6: 2 and b, circles) and a small detached mucus layer (Fig. 6: b, arrow). Whereas, the treatment of ulcerated rats with $200 \mathrm{mg} /$ $\mathrm{kg}$ b.w., and $400 \mathrm{mg} / \mathrm{kg}$ b.w., of RTE lead to the reduction of the whole stomach size, the disappearance of the ulcer crater (Fig. 6: 3 and 4), and induced the mucus production on the epithelial cells surfaces (Fig. 6: 4, square) and the arrangement of the mucosal layer (Fig. 6: $\mathrm{c}$ and d) to be similar to the rantidine-treated and control rats (Fig. 6: e and f).

Table 1 shows that the ulcer induction with $0.5 \mathrm{ml}$ of ethanol solution (80\%) in EtOH rats was accompanied with a significant increase $(p<0.01)$ of the gastric juice secreted as well as the ulcer index $(p<0.001)$ and a significant decrease of $\mathrm{pH}$ level $(p<0.01)$ and gastric mucus weight $(p<0.01)$ when compared with control group. Whereas pretreatment of ethanol ulcerated rats with RTE normalized as dose-dependant manner the above cited parameters

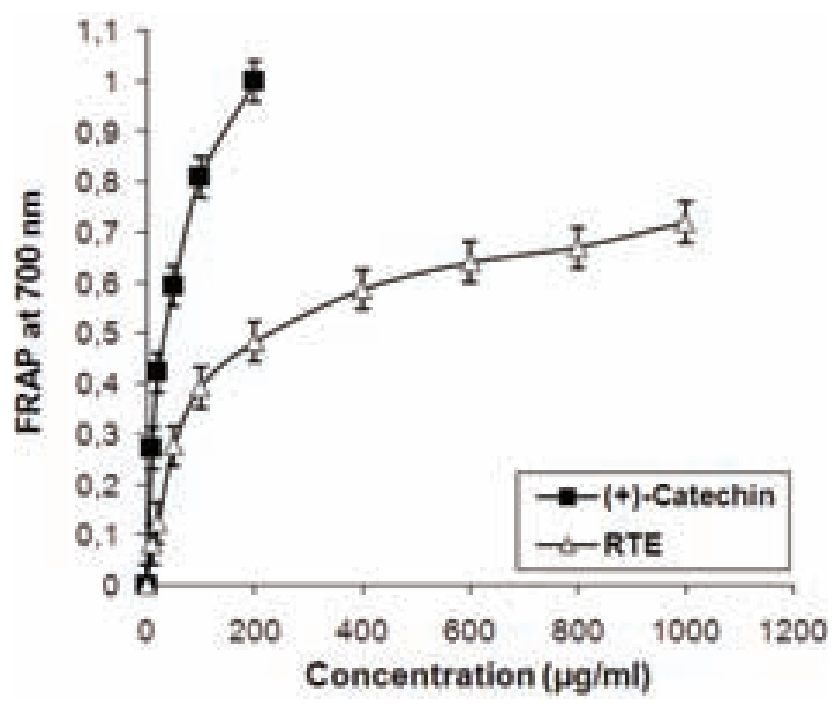

Figure 5. Ferric reducing power (FRAP) of Rhus tripartitum extract (RTE). (+)-Catechin was used as a positive control. 
Table 1. Effect of RTE on gastric secretion, $\mathrm{pH}$, mucus content and ulcer index in ethanol-induced ulcerated rats.

\begin{tabular}{lcccc}
\hline Treatments & $\begin{array}{c}\text { Gastric juice } \\
\text { volume }(\mathrm{ml} / 100 \mathrm{~g})\end{array}$ & $\mathrm{pH}$ & $\begin{array}{c}\text { Mucus } \\
\text { weight }(\mathrm{g})\end{array}$ & $\mathrm{UI}\left(\mathrm{mm}^{2}\right)$ \\
\hline Control & $0.89 \pm 0.4^{* *}$ & $4.8 \pm 0.5^{* *}$ & $134.6 \pm 0.73^{* *}$ & $0.00 \pm 0.0^{* * *}$ \\
EtOH & $3.6 \pm 0.8^{\dagger \dagger}$ & $2.1 \pm 0.3^{\dagger \dagger}$ & $86.92 \pm 0.61^{\dagger \dagger}$ & $32.51 \pm 0.6^{\dagger \dagger \dagger}$ \\
$\mathrm{RTE} 1+\mathrm{EtOH}$ & $2.1 \pm 0.6^{*}$ & $2.8 \pm 0.6^{*}$ & $121.9 \pm 0.84^{* *}$ & $14.87 \pm 0.4^{* *}$ \\
$\mathrm{RTE} 2+\mathrm{EtOH}$ & $1.7 \pm 0.2^{* *}$ & $3.6 \pm 0.8^{*}$ & $196.3 \pm 1.27^{* *}$ & $3.29 \pm 0.6^{* *}$ \\
$\mathrm{RTE} 3+\mathrm{EtOH}$ & $1.1 \pm 0.3^{* *}$ & $4.9 \pm 0.2^{* *}$ & $266.7 \pm 1.08^{* *}$ & $1.37 \pm 0.5^{* *}$ \\
Ran $+\mathrm{EtOH}$ & $0.84 \pm 0.2^{* *}$ & $5.1 \pm 0.4^{* *}$ & $132.1 \pm 0.74^{* *}$ & $1.68 \pm 0.2^{* *}$ \\
\hline
\end{tabular}

Values are expressed as means \pm S.D of measurement of 8 rats in each group. RTE, Rhus tripartitum extract; $\mathrm{EtOH}$, ethanol; Ran, ranitidine. Ethanol group was compared with control group and significance was taken at ${ }^{\dagger \dagger} p<0.01$ and ${ }^{\dagger \dagger \dagger} p<0.001$. RTE and ranitidine treated groups were compared with ethanol group and significance was taken at ${ }^{*} p<0.05,{ }^{* *} p<0.01$ and at ${ }^{* *} p<0.001$.

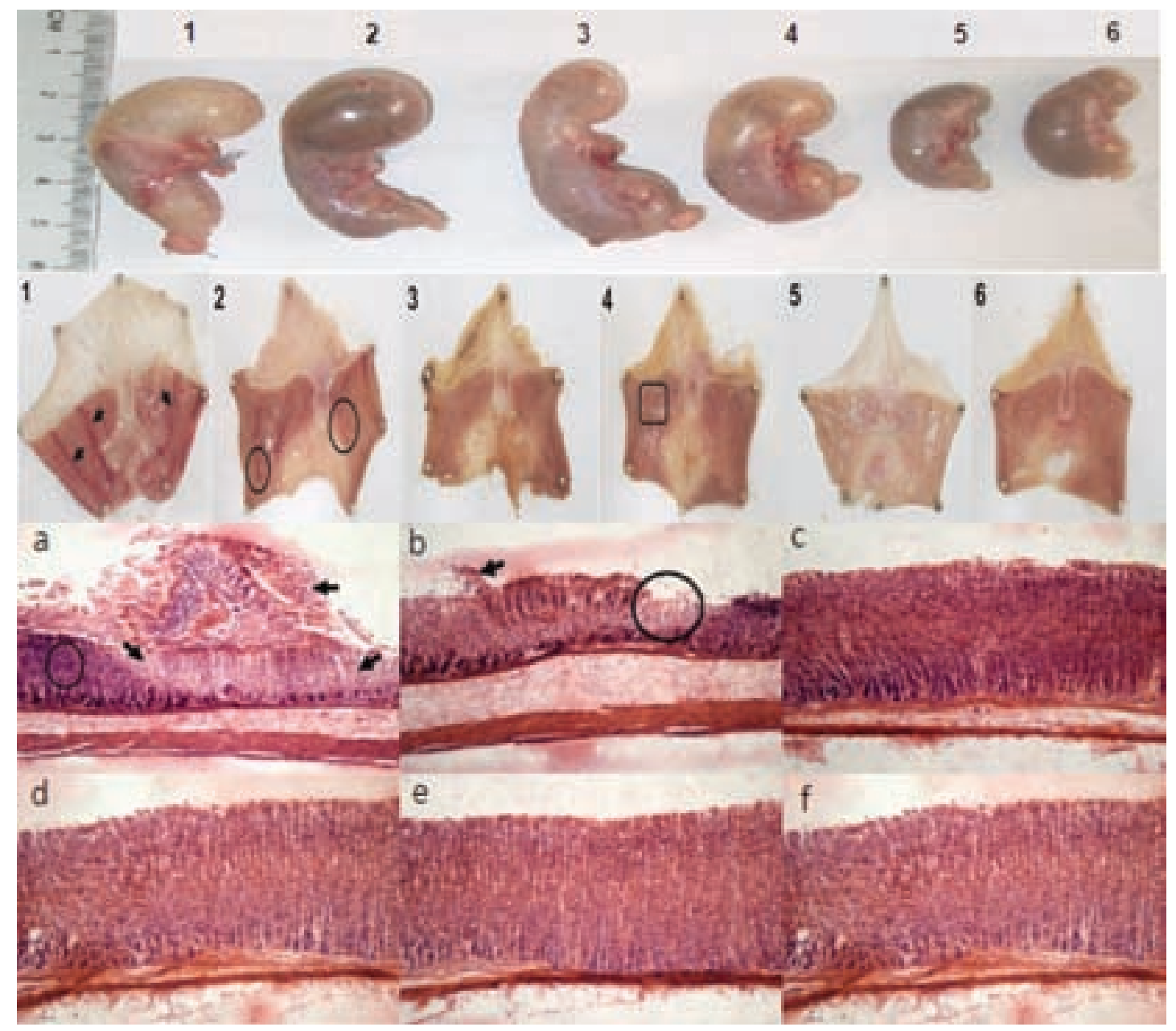

Figure 6. Photographs of the whole, dissected and sectioned stomachs from rats submitted to ethanol inducing gastric ulcer (sections were stained with hematoxylin and eosin; magnifications $\times 20$ ). Stomach from rat treated with $80 \%$ ethanol showing a large swelled stomach packed of gastric juice, a deepen hemorrhagic lesion of mucosal layer (1, arrows) and the neutrophil infiltration in the gastric mucosa (a, circle). Stomach from ulcerated rats pretreated with $50 \mathrm{mg}$ RTE $/ \mathrm{kg}$ b.w. appeared swelled, exhibited no deep and cicatrized gastric lesions when dissected, a narrow lesion crater (2, b, circle) and a small detached portion of mucus layer (b, arrow). Stomach from ethanol-ulcerated rats treated with $200 \mathrm{mg}$ RTE/kg b.w. (3) and $400 \mathrm{mg}$ RTE/kg b.w. (4) and ranitidine (5) showed a reduction of whole stomach size, absence of ulcer crater and proper arranged of mucosal layer (c, $\mathbf{d}$ and $\mathbf{e})$ almost similar to control (f). 
to near values registered in normal and ranitidine-treated groups.

Effect of RTE on biochemical parameters of ethanol-ulcerated rats

Fig. 7 shows the treatment effects of RTE on the activities of gastric antioxidants enzymes (SOD, CAT and GSH), the activities of MPO, the levels of gastric GSH and to the lipid peroxidation product (MDA) in rats ulcerated with ethanol. The treatment of EtOH group with $0.5 \mathrm{ml}$ of ethanol $(80 \%)$ significantly $(p<0.01)$ decreased the SOD, CAT, and GSH-Px activities, the GSH content and increased the MPO activity in rat's stomach tissues when compared with control group. Rather than reducing antioxidant enzymes activities, ethanol instillation significantly a

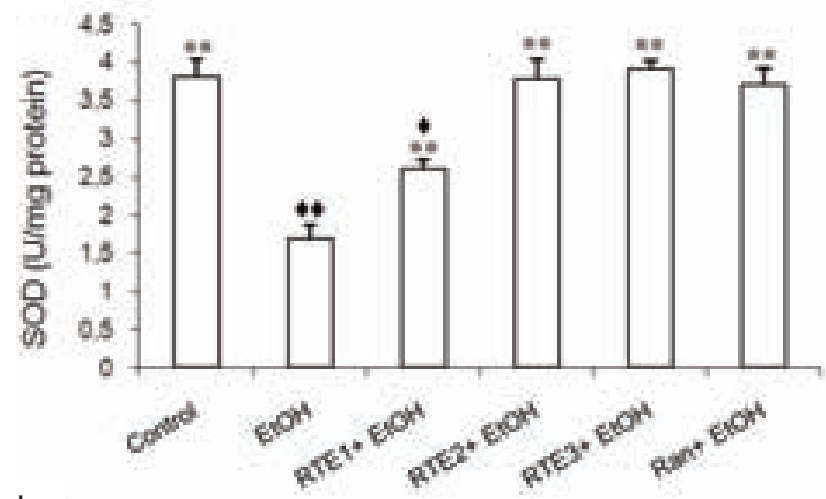

b

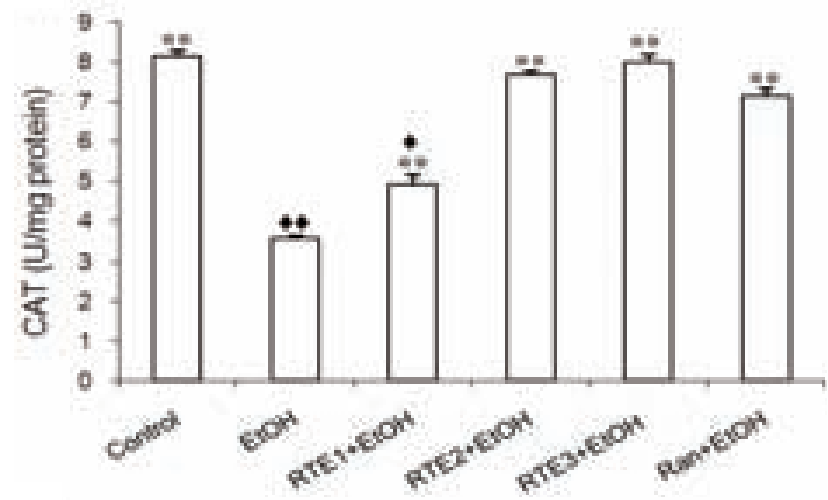

C

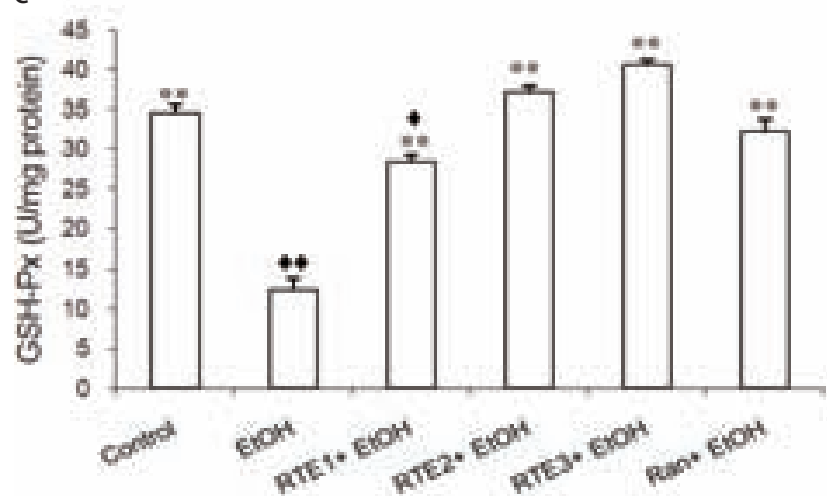

d

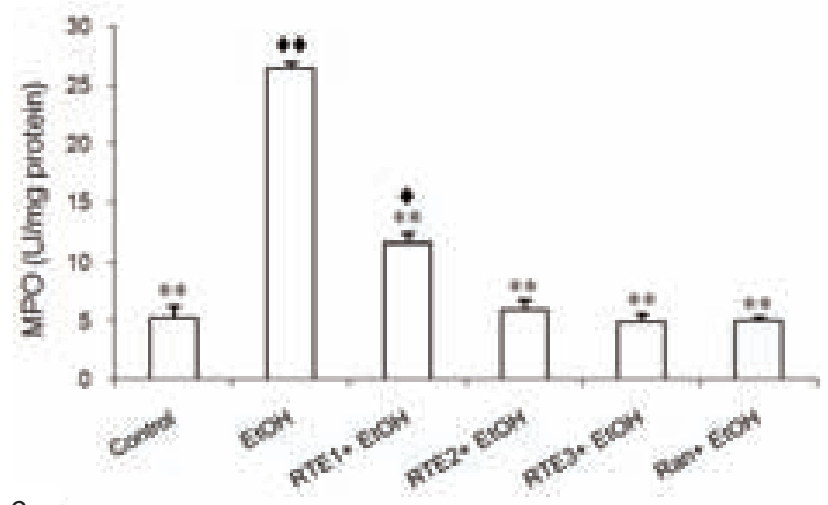

e

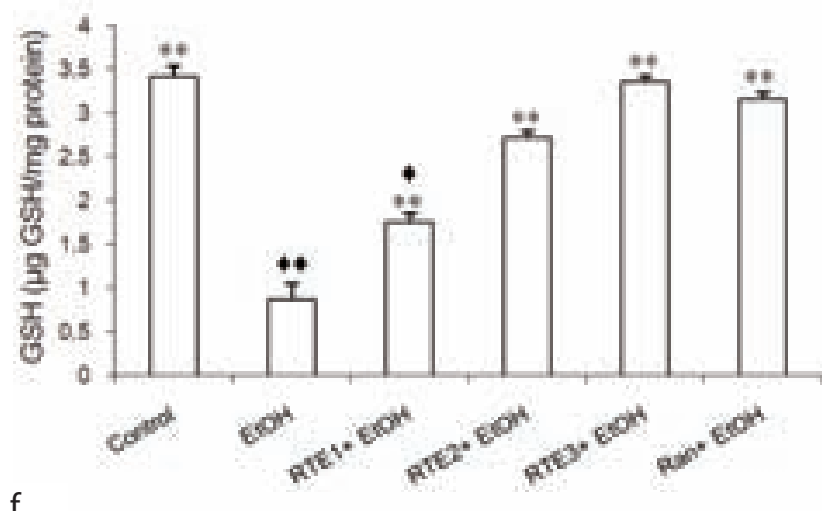

f

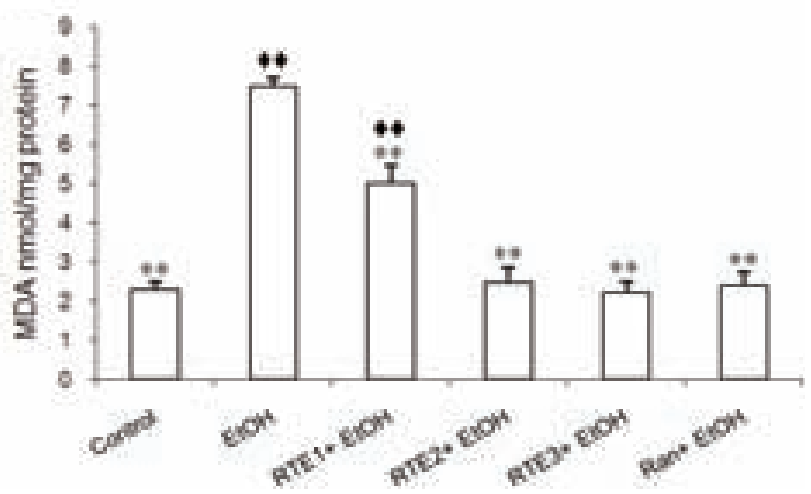

Figure 7. Effect of Rhus tripartitum extract (RTE) and ranitidine (Ran) treatments on the gastric superoxide dismutase (a), catalase (b) glutathionne peroxidase (c), myeloperoxidase (d) enzymes activities and the contents of reduced glutathione (e) and malondialdehyde (f) in ethanol ulcerated rats. Values are expressed as means $\pm \mathrm{SD}(n=8) .{ }^{*} p<0.05,{ }^{*} p<0.01$ versus ethanol treated group; $p<0.05$, $\bullet p<0.01$ versus control group. 
$(p<0.01)$ enhanced production of lipid peroxidation in rat's stomach tissues when compared with control rats (Fig. 7f). However, RTE supplement to ethanol- ulcerated rats significantly $(p<0.01)$ increased gastric SOD, CAT and GSH-Px activities and GSH level in dose-dependent manner, to reach normal values registered in ranitidine and control groups. In contrast, ranitidine and RTE treatments greatly lowered, in dose-dependent manner, the mucosal MPO activity and MDA level of the ethanol ulcerated rats almost to near control levels.

\section{Discussion}

The gastric ulcer is a repeating chronic affection, extremely frequent, with clear male prevalence. Exogenous compounds, mainly acetylsalicylic acid, NSAIDs and copious ethanol intake causes erosive lesions in the gastrointestinal mucosa (Jahovic et al. 2007). Several procedures are used to induce gastric ulcer in rats and each mode has its specific mechanism. NSAIDs like aspirin causes mucosal damage by interfering with prostaglandin synthesis (Rao et al. 2004). Pylorus ligation-induced ulcer is due to autodigestion of the gastric mucosa and breaks down of the gastric mucosal barrier (Sairam et al. 2002). Ethanol-induced gastric ulcers was reported to stimulate the formation of leukotriene $\mathrm{C} 4$ (LTC4), the neutrophil cells activation, the production of reactive oxygen species which in turn produces a direct gastric necrotizing action and reduces defensive factors like the secretion of bicarbonate and production of mucus (Jaiswal et al. 2011). Rather than inducing ulcer, ethanol could diffuse to the whole body and induced hematological and metabolism perturbation (Husain et al. 2001), for these reasons we chose ethanol to induce gastric ulcer. For the treatment of gastric ulcer, many pharmaceutical products including histamine (H2) receptor antagonists, proton pump inhibitors, antacids and anti-cholinergic have been used (Singh et al. 2008). However, most of these drugs have various undesirable side effects (Devi et al. 2007). In this framework it was of interest to seek natural product having antioxidants and antiulcerogenic properties. Although it has been reported that Rhus tripartitum root barks is used in treating ulcer in folk medicine, no experimental evidence has been reported. Thus, in the present study the RTE have been studied on three steps in order to investigate their beneficial effects against ethanol-induced ulcer: 1 ) by exploring their phenolic, flavonoids and polysaccharide contents, 2) by evaluating in vitro their radical scavenging activity and their reducing property, 3) and by studying their anti-ulcer activities in vivo.

The secondary metabolites like phenolics, flavonoids, tannins and polysaccharides found in all parts of plants such as leaves, fruits, seeds, roots and bark have been reported to be potent free radical scavengers and inhibitors of lipid peroxidation (Mathew and Abraham 2006). Phytochemical studies demonstrated that RTE contain high phenolic content in comparison with the phenolics level detected in Opuntia ficus indica $f$. inermis root extract, known for their antiulcerogenic effects (Alimi et al. 2010). In addition higher tannin content has been detected in RTE when compared with the level detected in Rhus oxyacantha fresh root bark extract (Tebourbi et al. 2006). The chemical study of RTE also revealed the presence of polysaccharide content but appeared lower than that the level detected in swallow root known for their antiulcerogenic effect (Srikanta et al. 2007). It has been demonstrated that phenolic, flavonoids, condensed tannins and polysaccharide possess an ideal structural chemistry for free radical scavenging activity which arise 1) from their high reactivity as hydrogen or electron donors, 2) from their ability to stabilize and delocalize the unpaired electron (chain-breaking function), and 3) from their potential to chelate metal ions (termination of the Fenton reaction) (Galati and O'Brien 2004; Chanda and Dave 2009; Zhong et al. 2010).

Ethanol consumption is known to be one of many factors responsible for gastric ulcer formation due to the generation of oxygen-derived free radicals (superoxide anions, hydroxyl radicals and lipid peroxides) (Li et al. 2008). In this fact, the antioxidant sources may also have antiulcerogenic activity. Therefore, in this study, the antioxidant activities of RTE were firstly in vitro studied.

The scavenging activity on DPPH radical is a world wide used method for the quantification of the radical scavenging activity in vitro (Jagtap et al. 2010). As shown in Figure 4, the DPPH radical scavenging activity of RTE increased with concentration increase. It was clear that RTE $\left(\mathrm{EC}_{50}=\right.$ $10 \pm 0.1 \mu \mathrm{g} / \mathrm{ml}$ ) exhibited a high scavenging activity, which appeared close to $(+)$-catechin $\left(\mathrm{EC}_{50}=6.77 \pm 0.2 \mu \mathrm{g} / \mathrm{ml}\right)$ activity. The radical scavenging activity of RTE could be related to their phenolics, flavonoids, condensed tannins or to their polysaccharide content. Antioxidative properties of these compounds arise from their high reactivity as hydrogen or electron donors (Chanda and Dave 2009). The RTE scavenging ability tested in vitro could foresee a possible antiulcerogenic effect in vivo.

The reducing power is associated with antioxidant activity and may serve as a significant reflection of the antioxidant activity (Oktay et al. 2003). Compounds with reducing power indicate that they are electron donors and can reduce the oxidized intermediates of lipid peroxidation processes, so that they can act as primary and secondary antioxidants. The reducing power of RTE was evaluated based on their ability to reduce the $\mathrm{Fe}^{3+}$-ferricyanide complex to the ferrous form according to the method of Chu et al. (2000). As shown in Fig. 5, the reducing activity of RTE correlated well with increasing concentration. We think that RTE phenolics 
and flavonoids content appear to function as good hydrogen donors and therefore should be able to reduce $\mathrm{Fe}^{3+}$ to $\mathrm{Fe}^{2+}$ form. The reducing activity of RTE could be attributed in the large part at flavonoids content due to their chelating ability of metal ions, such as iron and copper (Chanda and Dave 2009).

A synergistic reducing power could be also played by polysaccharide content detected in RTE. It has been reported that polysaccharides could have a reducing and antiulcerogenic activities (Galati et al. 2001; Zhong et al. 2010). The reducing ability attributed to phenolics, flavonoids and polysaccharide could confer to the RTE an in vivo antiulcerogenic effect.

Acute alcohol consumption has been considered as one of several factors causing the gastro-duodenal disorders such as gastric ulcer (Cadirci et al. 2007). La Casa and coworkers suggested that free radicals could be the main causes of gastric ulcer development, and suggested the xanthine oxydase as source (La Casa et al. 2000). Another study made by Hamauzu et al. (2007) shows that the free radicals generated by the neutrophil cells have a significant role in the development of gastric ulcer registered in ethanol-intoxicated rats. The study made by Kahraman and al. (2003) showed the increase in the MPO activity, biological indicator of the activated neutrophils, in ethanol-ulcerated rats. Our results also showed a significant $(p<0.01)$ increase of gastric tissues MPO activity in ethanol-ulcerated rats (Fig. 7d). The ethanol has the ability to degrade mucous membrane proteins and induce a local inflammation. This event calls upon the activated neutrophils migration, where they can produce and release hydrogen peroxide $\left(\mathrm{H}_{2} \mathrm{O}_{2}\right)$ and superoxide radicals $\left(\mathrm{O}_{2}{ }^{-}\right)$which worsens and makes deeper the ethanol initiated ulcer. In addition, excessive production of $\mathrm{H}_{2} \mathrm{O}_{2}$ in ulcer crater could contribute to the oxidation of ethanol in acetaldehyde via the catalase pathway (Cunningham and Van Horn 2003).

The acetaldehyde constitutes the most harmful ethanol metabolite which could, due to their nucleophilic property, induce the lipid peroxidation and the decrease of membranous GSH content in gastric epithelial cells. In the present study it was shown that the administration of ethanol significantly $(p<0.01)$ enhanced lipid peroxidation process producing MDA (Fig. 7f), the depletion of gastric cells membranous GSH content (Fig. 7e) and the over production of MPO. Our results are in agreement with those of Cadirci et al. (2007) and La Casa et al. (2000). In this situation we assist to the over production of gastric juice which becomes significantly $(p<0.01)$ acidified in comparison with control rats. This verity explains the swelling form observed in ethanol ulcerated rats.

The gastric ethanol toxicity results macroscopically in a redness mucous membrane on which appears hemorrhagic lesions and the significant reduction of the mucus quantity
(Table 1). The microscopic study of the histological sections shows the erosion of the gastric epithelial cells, the widening of the inter-glandular spaces and the infiltration of the neutrophiles in the ulcerated zones. These results confirmed our previous finding (Alimi et al. 2010). In normal conditions gastric cells possess a powerful antioxidant defense system, including SOD, CAT and GSH-Px which play a protective role against xenobiotics (Sehirli et al. 2008). In the present study it was shown that the administration of ethanol significantly $(p<0.01)$ decreased the activities of SOD, CAT and GSH-Px enzymes when compared with control rats. In contrast pre-treatment of ethanol-ulcerated rats with RTE preserved the activities of antioxidants enzymes cited above to near normal and decreased lipid peroxidation product (MDA) and MPO activity as dose-dependant manner. In histological sections RTE could preserve intact the gastric tissues from ethanol injury by enhancing gastric mucus production (Table 1), by healing the ulcer craters and keeping near normal epithelial cells arrangement.

From these results, it appeared that the preventive effect of RTE might be due to their suppression of leukocyte migration to the gastric mucosa, which could be indicated by lowered activity of MPO, a marker enzyme of activated neutrophiles. In our study, the RTE showed dose-dependent radical scavenging activity (Fig. 4), and reducing power (Fig. 5), which may in part be responsible for the anti-ulcer activity of the extract. The wealth of RTE in antioxidant compounds such as phenolic flavonoids, tannin and poysacharides could explain the suppression of leukocyte migration and thereby the antiulcerogenic affect. The antioxidant activity of RTE is confirmed in vivo by kipping near normal gastric antioxidant status in ethanol-ulcerated rats.

The active constituents of RTE especially the tannins may also have a contributory role to play in its anti-ulcer activity. Tannins are known to 'tar' the outermost layer of the gastric mucosa rendering it less permeable and more resistant to chemical and mechanical injury or irritation (Aniagu et al. 2005). The present study has shown that RTE probably antagonizes the aggressive factors (e.g. acid out pout, free radicals release), which play an important role in the pathogenesis of gastric ulcers (Kumar and Clarke 2002), while augmenting the defensive mucosal factors that protect the gastric mucosa from injury.

Flavonoids possess antioxidant properties in addition to strengthening the mucosal defense system through stimulation of gastric mucus secretion. The results of the present study showed a possible positive correlation between flavonoids content in RTE and mucus weight produced in RTE-treated rats. Table 1 shows that the mucus weight was in RTE3 group approximately twice higher than that in control and RTE1 animals.

Flavonoids can scavenge the reactive oxygen species (e.g. super-oxide anions) and free radicals produced by ethanol. 
These reactive intermediates are potentially implicated in ulcerogenicity. The gallic acid which was the only phenolic acid identified by HPLC in RTE could confer a radical scavenging and antisecrtary effects to RTE.

Another possible mechanism for the anti-ulcer activity of the RTE may be the polysaccharides' ability to bind to the surface mucosa and function as a protective coating. Diseases of the gastrointestinal system are often related with irritations and pathological changes in mucus membranes, and polysaccharide-containing plants are widely used in traditional therapy of such diseases. Recently, rhamnogalacturonans have been found to adhere significantly to colon mucous membranes, which may lead to a protective coating and shielding of the epithelia, subsequent rehydration and accelerated healing (Schmidgall and Hensel 2002). It has been also demonstrated that polysaccharide, the major compound detected in RTE, could forms a gelatinous layer on the gastric mucosa which enhance mucus synthesis (Galati et al. 2001) this fact explain the significant increase of mucus weight in animals pretreated with $400 \mathrm{mg} / \mathrm{kg}$ of RTE when comapred with thows receiving only $50 \mathrm{mg} / \mathrm{kg}$ of RTE.

In addition polysaccharides could form a strong complex with tannin and flavonoids therefore confer to RTE the binding-tarring-scavenging ability and constitute a strong antiulcerogenic complex.

In conclusion, this is the first evidence that RTE has an antioxidant and a gastro-protective effect on ethanol-induced gastric ulcer. Due to the richness of RTE in phenolic, flavonoids, tannin and polysaccharide contents, their antioxidant and their potent antiulcerogenic activities we show that RTE is a potential therapeutic option in the effective management of ulcer, thus justifying its widespread use by the local population, and was also of potential therapeutic interest to enhance their investigation as a digestive tract anticancer agent.

Conflict of interest: The authors have declared that there is no conflict of interest.

Acknowledgements. This research was funded by the Tunisian Ministry of Higher Education and Scientific Research through Integrated Physiology Laboratory, Faculty of Science of Bizerte and the Research Unit of Macromolecular Biochemistry and Genetics, Faculty of Sciences of Gafsa.

\section{References}

Aebi H. (1984): Catalase in vitro. Methods Enzymol. (Bergneyer H.U.) 105, 121-126

Alimi H., Hfaiedh N., Bouoni Z., Hfaiedh M., Sakly M., Zourgui L., Ben Rhouma K. (2010): Antioxidant and antiulcerogenic activities of Opuntia ficus indica $\mathrm{f}$. inermis root extract in rats. Phytomedicine 17, 1120-1126 http://dx.doi.org/10.1016/j.phymed.2010.05.001

Alimi H., Hfaiedh N., Bouoni Z., Sakly M., Ben Rhouma K. (2011): Evaluation of antioxidant and antiulcerogenic activities of Opuntia ficus indica $\mathrm{f}$. inermis flowers extract in rats. Env. Toxicol. Pharmacol. 32, 406-416 http://dx.doi.org/10.1016/j.etap.2011.08.007

Aniagu S. O., Binda L. G., Nwinyi F. C., Orisadipe A., Amos S., Wambebe C., Gamaniel K. (2005): Anti-diarrhoeal and ulcerprotective effects of the aqueous root extract of Guiera senegalensis in rodents. J. Ethnopharmacol. 97, 549-554 http://dx.doi.org/10.1016/j.jep.2005.01.009

Arun M., Asha V. V. (2008): Gastroprotective effect of Dodonaea viscosa on various experimental ulcer models. J. Ethnopharmacol. 118, 460-465 http://dx.doi.org/10.1016/j.jep.2008.05.026

Baoshan S., Jorge M. R., Isabel S. (1998): Critical factors of vanillin assay for catechins and proanthocyanidins. J. Agric. Food. Chem. 46, 4267-4274 http://dx.doi.org/10.1021/jf980366j

Ben Mansour H., Yatouji S., Mbarek S., Houas I., Delai A., Dridi D. (2011): Correlation between antibutyrylcholinesterasic and antioxidant activities of three aqueous extracts from Tunisian Rhus pentaphyllum. Ann. Clin. Microb. Anti. 10, 1-9

Cadirci E., Suleyman H., Aksoy H., Halici Z., Ozgen U., Koc A., Ozturk N. (2007): Effects of Onosma armeniacum root extract on ethanol-induced oxidative stress in stomach tissue of rats. Chem. Biol. Interact. 170, 40-48 http://dx.doi.org/10.1016/j.cbi.2007.06.040

Chanda S., Dave R. (2009): In vitro models for antioxidant activity evaluation and some medicinal plants possessing antioxidant properties: An overview. A. J. Microbiol. Res. 3, 981-996

Chugh T., Aronow W. S. (2011): Peptic ulcer disease. J. Biologic. Med. 1, 13-22

Chu Y. H., Chang C. L., Hsu H. F. (2000): Flavonoid content of several vegetables and their antioxidant activity. J. Sci. Food. Agric. 80, 561-566

http://dx.doi.org/10.1002/(SICI)1097-0010(200004)80:5<561:: AID-JSFA574>3.0.CO;2-\#

Cunningham C. C., Van Horn C. G. (2003): Energy availability and alcohol-related liver pathology. Alcoh Res Heal. 27, 291-299

Devi R. S., Narayan S., Vani G., Devi C. S. S. (2007): Gastroprotective effect of Terminalia arjuna bark on diclofenac sodium induced gastric ulcer. Chem. Biol. Interact. 167, 71-83 http://dx.doi.org/10.1016/j.cbi.2007.01.011

Djeridane A., Yousfi M., Nadjemi B., Boutassouna D., Stocker P., Vidal N. (2006): Antioxidant activity of some Algerian medicinal plants extracts containing phenols compounds. Food Chem. 97, 654-660 http://dx.doi.org/10.1016/j.foodchem.2005.04.028

Dubois M., Gilles K. A., Hamilton J. K., Rebers P. A., Smith F. (1956): Colorimetric method for determination of sugars and related substances. Anal. Chem. 28, 350-356 http://dx.doi.org/10.1021/ac60111a017

Flohe L. Gunzler W. A. (1984): Assays of glutathione peroxidase. Methods Enzymol. 105, 114-121 http://dx.doi.org/10.1016/S0076-6879(84)05015-1 
Galati E. M., Monforte M. T., Tripodo M. M., D’Aquino A., Mondello M. R. (2001): Antiulcer activity of Opuntia ficus indica (L.) Mill. (Cactaceae): ultrastructural study. J. Ethnopharmacol. 76, 1- 9 http://dx.doi.org/10.1016/S0378-8741(01)00196-9

Galati G., O’Brien J. P. (2004): Potential toxicity of flavonoids and others dietary phenolics: significance for their chemopreventive and anticancer properties. Free Radic. Biol. Med. 37, 283-287 http://dx.doi.org/10.1016/j.freeradbiomed.2004.04.034

Grzegorczyk I., Matkowski A., Wysokinska H. (2007): Antioxidant activity of extracts from in vitro cultures of Salvia officinalis L. Food Chem. 104, 536-541 http://dx.doi.org/10.1016/j.foodchem.2006.12.003

Hamauzu Y., Forest F., Hiramatsu K., Sugimoto M. (2007): Effect of pear (Pyrus communis L.) procyanidins on gastric lesions induced by $\mathrm{HCl} /$ ethanol in rats. Food Chem. 100, 255-263 http://dx.doi.org/10.1016/j.foodchem.2005.09.050

Husain K., Skott B. R., Reddy S. K., Somani S. M. (2001): Chronic ethanol and nicotine interaction on rat tissue antioxidant defense system. Alcohol 25, 89-97 http://dx.doi.org/10.1016/S0741-8329(01)00176-8

Jagtap U. B, Panaskar S. N., Bapat V. A. (2010): Evaluation of antioxidant capacity and phenol content in jackfruit (Artocarpus heterophyllus Lam.) fruit pulp. Plant Foods Hum. Nutr. 65, 99-104 http://dx.doi.org/10.1007/s11130-010-0155-7

Jahovic N., Erkanl G., İşeri S., Arbak S., Alican İ. (2007): Gastric protection by $\alpha$-melanocyte -stimulating hormone against ethanol in rats: Involvement of somatostatin. Life Sci. 80, $1040-1045$ http://dx.doi.org/10.1016/j.lfs.2006.11.036

Jaiswal S. K., Rao C. V., Sharma B., Mishra P., Das S., Dubey M. K. (2011): Gastroprotective effect of standardized leaf extract from Argyreia speciosa on experimental gastric ulcers in rats. J. Ethnopharmacol. 137, 341-344 http://dx.doi.org/10.1016/j.jep.2011.05.028

Kahraman A., Erkasap N., Koken T., Serteser M., Aktepe F., Erkasap S. (2003): The antioxidative and antihistaminic properties of quercetin in ethanol-induced gastric lesions. Toxicology 183, 133-142 http://dx.doi.org/10.1016/S0300-483X(02)00514-0

Khan H. A. (2004): Computer-assisted visualization and quantitation of experimental gastric lesions in rats. J. Pharmacol. Toxicol. Meth. 49, 89-95 http://dx.doi.org/10.1016/j.vascn.2003.10.004

Kumar P. J., Clarke M. L. (2002): Clinical Medicine. (5th edition), WB Saunders, UK

La Casa C., Villegas I., Alarcón de la Lastra C., Motilva V., Martín Calero M. J. (2000): Evidence for protective and antioxidant properties of rutin, a natural flavone, against ethanol induced gastric lesions. J. Ethnopharmacol. 71, 45-53 http://dx.doi.org/10.1016/S0378-8741(99)00174-9

Li C. Y., Xu H. D., Zhao B. T., Chang H. I., Rhee H. I. (2008): Gastroprotective effect of cyanidin 3-glucoside on ethanol-induced gastric lesions in rats. Alcohol 42, 683-687 http://dx.doi.org/10.1016/j.alcohol.2008.08.009

Lowry O. H., Rosenbrough N. J., Randall R. (1951): Protein measurement with the folin phenol reagent. J. Biol. Chem. 193, 265-275
Mahjoub M. A., Ammar S., Edziri H., Mighri N., Bouraoui A., Mighri Z. (2010): Anti-inflammatory and antioxidant activities of some extracts and pure natural products isolated from Rhus tripartitum (Ucria). Med. Chem. Res. 19, 271-282 http://dx.doi.org/10.1007/s00044-009-9190-z

Manrique G. D., Lajolo F. M. (2002) : FT-IR spectroscopy as a tool for measuring degree of methyl esterification in pectins isolated from ripening papaya fruit. Post. Biol. Technol. 25, 99-107 http://dx.doi.org/10.1016/S0925-5214(01)00160-0

Mathew S., Abraham T. E. (2006): In vitro antioxidant activity and scavenging effects of Cinnamomum verum leaf extract assayed by different methodologies. Food Chem. Toxicol. 44, 198-206 http://dx.doi.org/10.1016/j.fct.2005.06.013

Misra H. P., Fridovich I. (1972): The role of superoxide anion in the autooxidation of epinephrine and a simple assay for superoxide dismutase. J. Biol. Chem. 247, 3170-3175

Moron M. A., De Pierre J. W., Mannervick B. (1979): Levels of glutathione, glutathione reductase and glutathione-Stransferase activities in rat liver. Biochim. Biophys. Acta 582, 67-78 http://dx.doi.org/10.1016/0304-4165(79)90289-7

Navarini L., Gilli R., Gombac V., Abatangelo A., Bosco M., Toffanin R. (1999): Polysaccharides from hot water extracts of roasted Coffea arabica beans: Isolation and characterization. Carbohydr. Polym. 40, 71-81 http://dx.doi.org/10.1016/S0144-8617(99)00032-6

Ohkawa H., Ohishi N., Yagi K. (1979): Assay for lipid peroxides in animal tissues by thiobarbituric acid reaction. Anal. Biochem. 95, 351-358 http://dx.doi.org/10.1016/0003-2697(79)90738-3

Oktay M., Gulcin I., Kufrevioglu O. I. (2003): Determination of in vitro antioxidant activity of fennel (Foeniculum vulgare) seed extracts. Leb. Wissen. Technol. 36, 263-271 http://dx.doi.org/10.1016/S0023-6438(02)00226-8

O'Malley P. (2003): Gastric ulcers and GERD: the new «plagues» of 21 st century update for the clinical nurse specialist. Clin. Nurse Spec. 17, 286-289

http://dx.doi.org/10.1097/00002800-200311000-00008

Rao Ch. V., Ojha S. K., Reddy G. D., Rawat A. K. S., Rao G. M. M., Puspagandan P. (2004): Antidiarrhoeal activity of Argyreia speciosa flower: an ethnopharmacological study. Acta. Pharma. Turcica 46, 149-159

Sairam K., Rao Ch. V., Dora Babu M., Agrawal V. K., Goel R. K. (2002): Antiulcerogenic activity of methanolic extract of Emblica officinalis. J. Ethnopharmacol. 82, 1-9 http://dx.doi.org/10.1016/S0378-8741(02)00041-7

Schmidgall J., Hensel A. (2002): Bioadhesive properties of polygalacturonides against colonic epithelial membranes. Inter. J. Biol. Macromol. 30, 217-225 http://dx.doi.org/10.1016/S0141-8130(02)00036-3

Sehirli O., Tatlidede E., Yuksel M., Erzik C., Cetinel S., Yeğen B. C., Sener G. (2008): Antioxidant effect of alpha-lipoic acid against ethanol-induced gastric mucosal erosion in rats. Pharmacology 81, 173-180 http://dx.doi.org/10.1159/000111145

Shaker E., Mahmoud H., Mnaa S. (2010): Anti-inflammatory and anti-ulcer activity of the extract from Alhagi maurorum (camelthorn). Food Chem. Toxicol. 48, 2785-2790 
http://dx.doi.org/10.1016/j.fct.2010.07.007

Singleton V. L., Orthofer R., Lamuela-Raventos R. M. (1999): Analysis of total phenols and other oxidation substrates and antioxidants by means of Folin-Ciocalteu reagent. Meth. Enzymol. 299, 152-178 http://dx.doi.org/10.1016/S0076-6879(99)99017-1

Singh S., Khajuria A., Taneja S. C., Khajuria R. K., Singh J., Johri R. K., Qazi G. N. (2008): The gastric ulcer protective effect of boswellic acids, a leukotriene inhibitor from Boswellia serrata, in rats. Phytomedicine 15, 408-415 http://dx.doi.org/10.1016/j.phymed.2008.02.017

Srikanta B. M., Siddaraju M. N., Dharmesh S. M. (2007): A novel phenol-bound pectic polysaccharide from Decalepis hamiltonii with multi-step ulcer preventive activity. World. J. Gastroenterol. 39, 5196-5207

Tebourbi O., Trabelsi C., Ben Nasr C., Sakly M. (2006): Antioxidant activity of extract of rhus oxyacantha root cortex. Indian J. Exp. Biol. 44, 246-249

Valle J. D. (2008): Peptic ulcer disease and releated disorder. (Eds. A. S. Fauci, E. Braunwald, D. L. Kasper, S. L. Hauser, D. L.
Longo, J. L. Jameson and J. Loscalzo), 17 edition, Harrison's Principles of Internal Medicine, chapter 287, p. 1855, McGrawHill, NewYork

Xu W., Zhang F., Luo Y., Ma L., Kou X., Huang K. (2009): Antioxidant activity of a water-soluble polysaccharide purified from Pteridium aquilinum. Carbohyd. Res. 344, 217-222 http://dx.doi.org/10.1016/j.carres.2008.10.021

Zhao M., Yang N., Yang B., Jiang Y., Zhang G. (2007): Structural characterization of water-soluble polysaccharides from Opuntia monacantha cladodes in relation to their anti-glycated activities. Food Chem. 105, 1480-1486 http://dx.doi.org/10.1016/j.foodchem.2007.05.031

Zhong X. K., Jin X., Lai F. Y., Lin Q. S., Jiang J. G. (2010): Chemical analysis and antioxidant activities in vitro of polysaccharide extracted from Opuntia ficus indica Mill. cultivated in China. Carbohydr. Polym. 82, 722-727

http://dx.doi.org/10.1016/j.carbpol.2010.05.042

Received: June 11, 2012

Final version accepted: August 20, 2012 